\title{
CLÍNICA GESTÁLTICA INFANTIL E INTEGRALIDADE EM UMA UNIDADE BÁSICA DE SAÚDE
}

\author{
Gestalt Clinic for Children and Attention to Basic Health Integrality \\ Clínica Gestáltica Infantil e Integralidad en la Atención Básica de la Salud
}

Bruna Gonçalves Campos

Tatiana Bruno De Toledo

NiLTON JÚlio DE FARIA

\begin{abstract}
Resumo: $\mathrm{O}$ artigo consta de um relato de experiência com grupo de crianças em uma Unidade Básica de Saúde de Campinas-SP. As atividades tiveram como referência teórico-metodológica a Gestalt-terapia e produções teóricas acerca da saúde pública. Considerando-se a grande demanda de atendimento de crianças advindas das escolas e famílias, deu-se preferência por atenção em grupo, visando contemplar a concepção de saúde proposta pelo Sistema Único de Saúde; desta forma, a prática incluiu o manejo de atividades lúdicas e o exercício da clínica ampliada. As atividades lúdicas facilitam o acesso à compreensão dos significados atribuídos às vivências, visto que permitem à criança experimentar e reproduzir situações cotidianas em um ambiente que lhe possibilite o exercício de ajustamentos criativos. Ressalta-se a importância deste procedimento para que ocorra a presentificação dos sentimentos e a ampliação de awareness. A clínica ampliada possibilitou uma compreensão mais abrangente da realidade vivida pela criança, e de como ela contribui para a constituição da subjetividade. Desta forma, são apresentados elementos importantes para que o processo terapêutico com crianças ocorra visando à integralidade da atenção à saúde.
\end{abstract}

Palavras-chave: Saúde Pública; Integralidade; Psicoterapia Infantil; Gestalt-terapia; Atenção Básica em Saúde.

\begin{abstract}
The article is about the experience of a group of children in a basic health care general practice in Campinas-SP. The activities had as theoretical-methodological reference the gestalt-therapy and theoretical production around the public health. Considering the vast request for treatment from the schools and families, it was given preference to work in groups in order to look on the health conception proposed by the public health policy; so the engagement includes handling playful activities and the exercise of the expanded general practice. Playful activities facilitate the access to comprehension of the assigned meanings to their ways of living life, in order to allow children to try and reproduce daily routine situations in a helpful environment which enables creative adjustment exercises. The importance of this procedure is highlighted so that the presentification of the feelings and the expansion of awareness occur. The expanded clinic made possible a more broad comprehension of the children reality and how it contributed to the constitution of the subjectivity. Thus, important elements are presented so that the therapeutic process with children happens focusing on the attention to health integrality.

Keywords: Public Health; Integrality; Children's Psychotherapy, Gestalt therapy, Health Basic Attention.

Resumen: El artigo se trata de un relato de experiencia con un grupo de niños en una unidad de atención básica de salud en Campinas-SP. Las actividades tuvieron como referencia teórica-metodológica la Gestalt-terapia y producciones teóricas sobre la salud pública. Tomando en consideración la gran demanda de asistencia de niños provenientes de escuelas y familias, se dio la preferencia por atención en grupo, con la visión de contemplar la concepción de salud propuesta por la política de salud pública; así la práctica incluyó el manejo de actividades lucidas y el ejercicio de clínica ampliada. Las actividades lucidas facilitan el acceso a comprensión de los significados atribuidos a las vivencias, ya que permiten al niño experimentar y reproducir situaciones cotidianas en un ambiente que le permite el ejercicio de ajustes creativos. Se resalta la importancia de este procedimiento para que ocurra la presentificación de los sentimientos y la ampliación del awareness. La clínica ampliada permitió una comprensión más grande de la realidad vivida por el niño, y de como él contribuye para la constitución de la subjetividad. Así, son presentados elementos importantes que el proceso terapéutico con niños ocurra visando la integración de atención a la salud. Palabras-clave: Salud Publica; Integralidad; Psicoterapia Infantil; Terapia gestalt; Atención Básica de Salud.
\end{abstract}

\section{Introdução}

O presente artigo consta de um relato de experiência com grupo de crianças no contexto da saúde pública, em uma Unidade Básica de Saúde na cidade de Campinas (São Paulo, Brasil). O tema que será discutido surgiu a partir da identificação da necessidade de maior emba- samento bibliográfico na área de atuação com crianças, principalmente no que se refere ao atendimento em grupo de crianças em Unidades Básicas de Saúde, tendo como referencial teórico a abordagem gestáltica.

$\mathrm{O}$ atendimento baseado nesta abordagem valoriza o constante vir-a-ser no aqui-e-agora do setting terapêutico, onde é possível lidar com os fenômenos que se apresen- 
tam. No entanto, pouco há publicado sobre estes princípios e suas relações com a concepção de saúde proposta pelo Sistema Único de Saúde. Com a intenção de aproximar-se da realidade infantil, utilizam-se métodos lúdicos que favorecem a expressão de sentimentos, fantasias e vivências de situações cotidianas. Isso permite a ampliação de awareness da criança e, assim, o reconhecimento de novas possibilidades de escolha, favorecendo o ajustamento criativo.

Ressalta-se a importância da visão holística do ser humano, atendendo aos princípios da Gestalt-terapia e do Sistema Único de Saúde, concomitantemente. Com isso, buscou-se uma atuação que valoriza a integralidade do indivíduo através de ações que extrapolam os limites da clínica tradicional.

\section{Sistema Único de Saúde e integralidade da atenção}

O modelo de saúde baseado na visão biomédica, em que se tem como foco a cura da doença, define a saúde como sendo a ausência de sintomas. Esta prática não considera o indivíduo em sua integridade, pois não tem em vista a dimensão da subjetividade do sofrimento. A desvinculação deste conceito tem sido a grande busca do Sistema Único de Saúde (SUS), de acordo com os seus princípios. A proposta deste serviço é recente, mas já trouxe diversas mudanças em direção à integralidade do cuidado, igualdade do acesso à saúde e multidisciplinaridade no trabalho. Seus princípios valorizam a prevenção e promoção da saúde, com o objetivo de propiciar uma melhor qualidade de vida da população.

A partir da Constituição de 1988, estabeleceram-se como fatores de grande influência na saúde: o meio físico (condições geográficas, sanitárias, alimentação, habitação, etc.); o meio socioeconômico, a cultura e os fatores biológicos. Também se determinou o direito de todos os cidadãos ao acesso aos serviços que visem à promoção, proteção e recuperação da saúde, sendo o poder público o responsável por provê-los à população. Por fim, decretou-se o Sistema Único de Saúde (SUS), de "caráter público, formado por uma rede de serviços regionalizada, hierarquizada e descentralizada, com direção única em cada esfera de governo, e sob controle dos seus usuários" (Ministério da Saúde / Secretaria Nacional de Assistência à Saúde, 1990, p. 4).

O conjunto de serviços oferecidos pelo SUS, assim, atua para um fim comum - proteção, promoção e recuperação da saúde - e parte dos seguintes princípios doutrinários: universalidade, ou seja, a garantia de atenção à saúde a todo e qualquer cidadão; equidade, o atendimento de acordo com a necessidade que cada caso requeira; integralidade, o reconhecimento da totalidade: do indivíduo integrante de uma comunidade; das ações de promoção, proteção e recuperação da saúde, e também, das unidades prestadoras de serviços (Ministério da Saúde / Secretaria Nacional de Assistência à Saúde, 1990).

A organização do SUS é regida pelos seguintes princípios: regionalização e hierarquização, em que os serviços devem ser organizados em níveis de complexidade tecnológica, dispostos numa área geográfica delimitada e com a definição da população a ser atendida. Devem ser possíveis a uma determinada população todas as modalidades de assistência. A resolubilidade trata da capacidade de resolução com eficácia da demanda. A descentralização é a redistribuição de responsabilidade entre as esferas de Governo, sendo o município o principal encarregado pelas ações em saúde de seu território. E, por fim, o princípio do controle social visa à participação da comunidade nas decisões e formulações de políticas relacionadas ao tema.

Para a realização desta nova perspectiva, o Sistema Único de Saúde (SUS) buscou as seguintes propostas de auxílio: a Estratégia da Atenção primária à saúde (APS)/ Atenção Básica (AB) e o Programa de Saúde da Família (PSF).

A Atenção Básica à Saúde deve atender a um território delimitado, e funcionar como a porta de entrada para o atendimento com resolubilidade às principais necessidades primárias da população. As demandas em saúde que precisam de serviços que envolvam maior complexidade tecnológica devem ser referenciadas a outros setores de saúde. A integralidade do serviço é realizada a partir de um trabalho interdisciplinar, entre profissionais, e intersetorial, com medidas sanitárias, educacionais, entre outras, de acordo com as peculiaridades da população abrangida (Tanaka \& Ribeiro, 2009).

A Estratégia de Saúde da Família foi regulamentada em 1994 pelo Ministério da Saúde, com o objetivo de aperfeiçoar e humanizar a assistência básica no Brasil. Foca-se no trabalho em conjunto com usuários, famílias e comunidade (Ministério da Saúde / Secretaria de Atenção à Saúde / Departamento de Atenção Básica, 2006). Através da relação de corresponsabilidade da equipe de saúde com a população, cria-se um vínculo de compromisso com os usuários do serviço (Ministério da Saúde. Brasília / Ministério da Saúde / Secretaria de Atenção à Saúde, 1997).

A articulação entre a saúde mental e a atenção básica ocorreu apenas a partir de 2001, com documentos desenvolvidos pela Coordenação Geral de Saúde Mental, que teve como principal diretriz o apoio matricial de saúde mental às equipes de PSF. Porém, apenas no ano de 2007 foi aprovada a inclusão da saúde mental como prioridade no Pacto pela Vida (Ministério da Saúde / Secretaria de Atenção à Saúde / Departamento de Atenção Básica, 2006).

O apoio matricial (equipe de apoio), de acordo com Figueiredo \& Campos (2009), "é um suporte técnico especializado que é ofertado a uma equipe interdisciplinar de saúde a fim de ampliar seu campo de atuação e qualificar suas ações” (p.130). Quando realizado por profissionais 
da área de Saúde Mental, "estes podem contribuir para uma atenção ampliada em saúde que contemple a totalidade da vida dos sujeitos" (p.130). Assim, é possível a compreensão dos determinantes objetivos na constituição do binômio saúde/doença, bem como a distinção de sofrimentos psíquicos individuais e sociais cotidianos, que podem ser acolhidos pela equipe, daqueles que necessitam de uma atenção especializada.

Verifica-se que o ideal do SUS está distante da realidade socioeconômica e histórico-cultural do país. Há um longo caminho a ser percorrido, e para isso é necessário que haja investimentos direcionados ao aprimoramento da saúde pública. É importante ainda destacar a necessidade de transformar teoria em prática nos serviços atuais relacionados à saúde no país, desenvolvendo práticas menos fragmentadas, em conjunto com uma maior integração e conscientização dos profissionais, para buscar promover saúde e estimular a autonomia dos usuários.

Pode-se perceber que a nova forma de compreender a saúde tem como base o indivíduo e sua totalidade - o que nos remete aos princípios da Gestalt-terapia e sua visão holística do ser humano, buscando a superação do modelo biomédico. Este modelo tradicional trata o indivíduo analisando-o em partes, em detrimento do todo, ou seja, fazem-se diagnósticos imprecisos baseados em um estudo fragmentado do fenômeno. Neste contexto, o indivíduo acaba se transformando em "sintoma", e o trabalho de saúde permanece com seu foco centrado em técnicas que buscam apenas a prevenção e cura, e não a promoção à saúde, desconsiderando as dimensões objetivas e subjetivas na constituição do sofrimento psíquico.

A promoção à saúde é um incentivo ao crescimento, à ampliação da consciência e autonomia do indivíduo que, assim como proposto na Gestalt-Terapia, facilitaria o desenvolvimento do autoapoio e autorregulação do indivíduo e da comunidade, necessitando de menores ações remediativas.

\section{Gestalt-terapia e Saúde}

A Gestalt-terapia é uma abordagem que valoriza o existir, o ser no mundo, a espontaneidade e autenticidade do indivíduo. Através de sua visão de homem, possibilita ao terapeuta enxergá-lo em sua singularidade e totalidade a partir da relação que se estabelece no aquiagora. Acredita-se nas potencialidades e capacidade de movimento do ser humano.

Concebe-se o homem como um ser de liberdade, com possibilidades e escolhas, sendo assim livre de determinações diretas. O homem é um ser no mundo que age ativamente sobre ele, ao mesmo tempo em que recebe influências em uma relação recíproca; sendo assim, indivíduo e mundo se constituem. Trabalha-se com a ideia de que o ser humano é responsável pelo que acontece consigo, por isso é necessário que se desenvolva o autoapoio. Isso é possível por meio da ampliação de awareness, o que possibilita a compreensão e utilização de recursos próprios para lidar com as circunstâncias diárias, facilitando a ascensão da autonomia.

A metodologia utilizada é a fenomenológica, que estuda como os fenômenos se manifestam na consciência, como estes realmente se apresentam no momento, deixando entre parênteses pré-conceitos, teorias, hipóteses e valores. Estes princípios podem ser observados na proposição de Benjamin (2004), ao salientar que "compreender” significa nos livrarmos do nosso referencial e adotarmos o do outro, assim como ouvir não somente o que está sendo dito, mas também sugerido, empaticamente, ou seja, participar do mundo interior do outro, porém preservando a própria individualidade.

Utiliza-se de uma abordagem holística que enxerga o organismo como totalidade e o fenômeno como existente a partir do momento que é apreendido. A relação sujeito-objeto é de complementaridade, por isso não tem como dissociá-los. Esta impossibilidade de fragmentação rompe com a idéia de determinação de um sobre o outro (Juliano, 1999). O princípio básico é o da organização do todo na significação e percepção do fenômeno, ou seja, o homem não analisa partes isoladas do todo, sendo ele também um organismo unificado, no qual vontades, percepções, pensamentos, problemas fisiológicos devem ser verificados como uma totalidade.

O conceito de saúde em Gestalt-Terapia implica a capacidade do indivíduo de manter um bom contato consigo e com seu contexto, perceber possibilidades de escolha na sua atuação no mundo, de maneira a responsabilizar-se por suas atitudes. A saúde é um movimento para a vida, um constante vir-a-ser, visando ao equilíbrio, ou seja, uma autorregulação satisfatória com o meio (Rodrigues, 2000).

Segundo Antony (2010), o indivíduo saudável, através do processo de autorregulação desenvolve-se sendo capaz de estabelecer uma hierarquia de necessidades. Por meio de sua interação com o ambiente age de maneira criativa, a fim de satisfazê-las. Para a autora, "saúde é viver experimentando e integrando todas as possíveis formas de manifestação do nosso ser. É um movimento constante de busca de novidades nutritivas no campo organismo/ambiente" (p.81).

A partir do momento em que essas necessidades não são satisfeitas, os sintomas surgem como tentativas de ajustamentos criativos (comportamentos, gestos, pensamentos, tensões corporais) para neutralizar a angústia, sinalizando que uma necessidade importante não está satisfeita e, por consequência, uma gestalt está aberta. $\mathrm{O}$ adoecer representa uma forma de autorregulação que revela uma personalidade que usa recursos psíquicos singulares para enfrentar o sofrimento, a dor, a tensão (Antony, 2010).

Frazão (conforme citada por D’Acri, 2007) ressalta que a busca repetitiva pelo fechamento de gestalten inacabadas, que configuram o sintoma na tentativa de restaurar 
um equilíbrio, é compreendida como um "ajustamento criativo disfuncional”. Segundo Lizias (2010), quando o indivíduo permanece com o repertório limitado e estereotipado de comportamentos, limita o surgimento de novas figuras e experiências, o que enrijece sua espontaneidade e não possibilita que haja mudança.

\section{A Clínica Infantil}

O trabalho com crianças necessita de uma visão ampla e sistêmica por parte do terapeuta. É importante, também, destacar que os comportamentos que constituem as queixas apresentadas, apesar de causarem grande grau de sofrimento para a família e/ou para a criança, nada mais são que a tentativa desta de se autorregular.

A criança atribui um significado ao seu mundo diferentemente do adulto. É preciso considerar esse aspecto durante o ouvir. Ouvir a criança é tentar compreender o significado do que diz, estimulando sua espontaneidade e tentando evitar que sejam feitas restrições impostas pelo referencial do adulto.

O funcionamento e a dinâmica da criança, seu jeito de transmitir ideias, pensamentos, sentimentos e a forma como entra em contato e se relaciona com o meio são os focos de atenção do gestalt-terapeuta, já que este não vai trabalhar com as causas dos sintomas (Antony, 2010). O modo com que a criança vivencia o contato e dá sentido aos diversos campos em que está inserida pode ser compreendido a partir da maneira que ela utiliza seu potencial criativo nas sessões psicoterápicas.

A atitude do psicoterapeuta com crianças deve ser divergente daquela utilizada com adultos, já que elas não costumam estabelecer reflexões sobre o tema que julgam sentir necessidade de compreender. De acordo com Lizias (2010), “(...) acompanhamos o fluxo de intencionalidades de cada movimento da criança e participamos de seu mundo lúdico de cores e formas, aproximando-se de suas intensidades delicadas a cada momento" (p. 68).

Assim, a prática é realizada com o acervo de técnicas e experimentos em que é imprescindível respeitar o movimento, a espontaneidade e a singularidade da criança, preservando seu potencial de escolha das atividades a serem realizadas durante a sessão. Também se pode estabelecer uma conversa reflexiva com o cliente a respeito do que foi vivenciado. Neste processo, é necessário que haja um bom contato e uma boa relação, propiciados pela presença autêntica e segura do terapeuta (Antony, 2010).

Ribeiro (1994) descreve os experimentos como ferramentas válidas e estimulantes, que auxiliam na compreensão das profundidades da personalidade, e na ampliação das fronteiras do self. De acordo com Oaklander (1980), "não importa que técnica específica seja usada, o bom terapeuta permanece com o processo que evolui junto com a criança. O procedimento ou a técnica é um mero catalisador" (p. 219). Os experimentos facilitam a obser- vação dos mecanismos de evitação que podem estar sendo utilizados pelo cliente em forma de ajustamentos criativos. Dentre esses, ressaltam-se como mais aparentes, as introjeções advindas do mundo do adulto e as projeções realizadas pelas crianças.

O trabalho com crianças ocorre na dinâmica do contexto terapêutico. Para uma maior compreensão de seu campo vivencial, é importante o contato com os pais e, quando necessário, com a escola Lizias (2010). O contato com a escola, de acordo com Aguiar (2005), apresenta as seguintes finalidades: conhecimento da criança no contexto escolar a partir da observação do ambiente e coleta de informações para intervir, fornecendo orientações aos profissionais envolvidos.

Deve-se, porém, ressaltar a importância de lidar com a criança conforme ela se apresenta, e não se apoiar em informações a priori, que podem ser fornecidas através de cartas da escola, testes realizados e relatórios diagnósticos. Isto permite que se estabeleça um contato sem julgamentos e haja a relação com a criança no aqui-agora (Oaklander, 1980).

Às vezes, os pais ou responsáveis "responsabilizam" a criança por um desequilíbrio que ocorre na dinâmica familiar, e que na maioria das vezes não é percebido pela família, fato que nos comprova a necessidade de haver um trabalho associado às famílias. Os objetivos deste são ouvi-los a respeito do andamento da terapia e da criança como um todo, escutar os assuntos emergentes pelos pais, fornecer informações referentes ao desenvolvimento infantil, quando houver demanda, e oferecer devolutivas importantes ao processo psicoterapêutico (Aguiar, 2005).

Além disso, o envolvimento de pais ou responsáveis no processo terapêutico da criança permite a compreensão de como são as relações entre as pessoas daquela família, como, por exemplo, o quanto de expectativas os adultos depositam nas crianças, quais as projeções, deflexões ou outros modos de evitação são atribuídos às crianças. Esta compreensão favorece o desenvolvimento de awareness dos adultos envolvidos, possibilitando mudanças significativas da dinâmica familiar.

É importante que os pais falem na presença da criança a respeito do que os levou a buscar auxílio psicológico. Esta atitude tem o sentido de aliviar as fantasias da criança sobre o que está errado, visto que geralmente elas imaginam algo pior que a realidade. É possível, através desta situação, observar a dinâmica da relação entre os pais e o filho, as reações da criança, bem como as versões de todos os lados. Tenta-se, a todo o momento, incluir a criança na conversa, demonstrando respeito e interesse pelo que ela pensa, sente e faz (Oaklander, 1980).

A essência de todo o trabalho está na relação dialógica formada entre a criança e o terapeuta. Para isto, é necessária a presença genuína deste, sendo esta atitude, de colocar-se no lugar do outro, o reconhecimento da criança e de suas potencialidades (Aguiar, 2005). 


\section{Relato de uma Experiência}

Faremos agora um relato e discussão de experiência em grupo terapêutico com crianças, vivenciado por duas discentes do último ano do curso de Psicologia da Pontifícia Universidade Católica de Campinas em uma situação de estágio obrigatório em Saúde/Clínica. O campo de prática é uma Unidade Básica de Saúde, no território noroeste da cidade de Campinas, e as atividades foram supervisionadas semanalmente pelo docente responsável pela disciplina.

O atendimento em grupo com crianças foi importante, porque permitiu a interação entre os seus membros, facilitando a socialização entre eles. Por meio de técnicas lúdicas foi possível a troca de experiências e a vivência de situações cotidianas, que eram atualizadas no aquiagora, trabalhadas coletivamente; estas experiências possibilitaram a ressignificação do vivido como geradores de algum tipo de sofrimento para a criança.

Os encontros com as crianças foram efetuados pelas duas estagiárias que se revezavam entre os papéis de terapeuta e coterapeuta; a alternância de papéis se dava a partir da percepção momentânea das terapeutas, que consideravam as demandas das crianças em suas dimensões relacionais e práticas. Esta atitude auxiliou de maneira significativa o desempenho do processo executado, facilitando a observação mais ampla do que ocorreu no grupo. A condição de awareness das terapeutas, desta forma, foi fundamental para que se pudesse desenvolver a elaboração do pensamento diagnóstico amplo, favorecendo intervenções mais precisas.

A psicoterapia infantil demandou técnicas e experimentos lúdicos que tinham sempre uma finalidade, porém não um resultado esperado; isto implica dizer que os recursos teciam um objetivo experiencial, tais como favorecer relacionamento entre os integrantes do grupo, avaliar habilidades perceptomotoras, cognitivas, emocionais, sociais, dentre outros; mas não deveriam visar a uma determinada mudança, seja qualquer que fosse.

Durante sua execução, qualquer movimento da criança foi acompanhado pelas estagiárias. Assim, permitiuse que o fenômeno se apresentasse como ele era de forma espontânea e autêntica.

No momento dos atendimentos foi necessária a suspensão de ideias e valores pessoais, possibilitando o desenvolvimento da awareness das terapeutas, no aquiagora. $\mathrm{O}$ ambiente terapêutico foi um local de escuta à criança, tendo em vista seu mundo vivido, deixando-a circular naturalmente por seu espaço vivencial. Foram ressaltados determinados limites com o intuito de se manter um convívio social em que se considerava o outro, assim como os meios disponíveis para a realização das atividades, como, por exemplo, a manutenção do espaço físico e dos recursos materiais utilizados. Foi indispensável que houvesse o respeito ao próximo para que a criança compreendesse o limite entre o eu e o outro.
No processo terapêutico, forneceram-se opções com o intuito de identificar o potencial de escolha, competições, cooperações e consenso do grupo. Como já referido, foram propostos experimentos que possibilitam a avaliação e intervenção sob dimensões cognitivas, como jogos de estratégia e raciocínio; emocionais, identificados nos jogos de sorte, como dados ou roletas; e perceptomotoras, verificados nos jogos de execução.

Pôde-se trabalhar com uma gama de opções lúdicas como jogos industrializados ou criados pelos membros do grupo, pinturas, dramatizações, construções de histórias, colagens, entre outros. Utilizou-se um arsenal de materiais: diferentes tipos de papéis (sulfite, crepom, cartolina, jornal, revista), caneta hidrocor, lápis de cor, giz de cera, cola colorida, glitter, fantoches, bonecos e brinquedos diversos.

As atividades possibilitaram a identificação de movimentos que indicassem o ciclo de abertura e fechamento de gestalten, a interrupção de contato e o uso de mecanismos neuróticos, por meio do esquema de funcionamento de cada criança demonstrado em seus valores culturais, seus gestos e relações dialógicas. Com isso, o pensamento diagnóstico pôde ser elaborado como um processo contínuo e dinâmico, tratando-se de hipóteses que auxiliaram na condução do trabalho em cada um dos encontros.

A partir do pensamento diagnóstico realizado durante o encontro com a criança, foi possível ao terapeuta propor opções de atividades dirigidas, que eram escolhidas e guiadas pelo próprio cliente, como experiências com jogos industrializados ou construídos livremente pelas crianças, atividades de desenho individual e/ou cooperativo, histórias com fantoches, construção individual ou em grupo com massa de modelar ou lego. Desta forma, as atividades lúdicas colocavam-se, ao mesmo tempo, como meio de construção de pensamento diagnóstico e de intervenção, sucessivamente.

Vale destacar os desenhos cooperativos que foram realizados em dois momentos diferentes. Em um deles, utilizando-se de cartolina, lápis de cor, cola colorida e caneta hidrocor, foi proposto que se fizesse um desenho em conjunto, escolhendo o tema por consenso. A outra forma de execução necessitou de uma folha de papel sulfite para cada integrante do grupo, giz de cera, lápis de cor, cola, barbante e palito de sorvete. O procedimento consistiu em cada um iniciar um desenho por tempo determinado e trocá-lo com outra criança para dar continuidade ao desenho alheio. Essa estratégia teve como objetivo identificar e trabalhar a cooperação e a competição, visando desenvolver a percepção do eu e do não-eu, enfocandose dimensões de frustrações, aceitação, socialização, de forma a favorecer o ajustamento criativo.

Salienta-se a importância de envolver os responsáveis no processo terapêutico; portanto, já no primeiro atendimento foi solicitado que os mesmos participassem junto dos filhos. Neste momento escutavam-se as queixas e expectativas dos pais, bem como a opinião das crianças 
sobre o que estava sendo falado. Desde então foi possível ter indícios de como era a relação entre ambos e estabelecer as condições do contrato. Em seguida, a outra metade da sessão era dedicada a uma primeira conversa a sós com as crianças, com o intuito de escutá-las sem a presença dos adultos. Com isso, verificavam-se a fala e o comportamento dos clientes nesta situação. Além disso, oferecia-se uma atividade livre às crianças que possibilitasse a construção de um vínculo entre elas, e entre elas e as terapeutas.

A cada ocorrência de três encontros somente com as crianças, o quarto era realizado em conjunto com os pais, quando foram trabalhadas as necessidades e expectativas de ambos, além de possibilitar a observação das relações pais-filho; para tanto, eram propostas atividades para serem executadas em conjunto.

No encontro inicial, como já descrito, trabalhou-se com os pais e os filhos a exposição dos motivos que os levaram a procurar o atendimento psicológico, e a opinião de ambos sobre as mesmas. Em seguida, apenas as crianças permaneceram na sala para que pudessem expor, por elas mesmas, estes motivos ou algo a mais que desejassem.

Após três sessões com as crianças, os pais foram chamados para uma sessão em conjunto; nesta ocasião foi proposta a realização de uma atividade de pintura em que estes tiveram que desenhar o que eles imaginavam que os filhos faziam nos atendimentos, enquanto as crianças realizaram um desenho que representasse o que elas desempenhavam no espaço terapêutico. Tal atividade teve como objetivo avaliar e discutir como os clientes vivenciavam o processo terapêutico, o diálogo existente entre crianças e seus responsáveis, a desmistificação de crenças dos pais acerca do trabalho que estava sendo desenvolvido, bem como expectativas para os próximos atendimentos.

Dentre as atividades realizadas, houve a proposição de um jogo de mímica em que os pais deveriam adivinhar a imitação dos próprios filhos e vice-versa. O objetivo era o de identificar como se estabelecia a relação entre eles se era de cooperação ou competição, o grau de hierarquia na relação, manipulações etc -; verificar como reagiam às dificuldades e frustrações, e se havia uma ajuda recíproca. Além disso, ao longo da experiência foram pontuados esses aspectos ao grupo, para propiciar uma discussão e o desenvolvimento de awareness.

Outro exemplo de experimento utilizado foi um desenho em conjunto, entre pais e filhos, no qual deveriam representar algum lugar ao qual gostavam de ir juntos. Teve-se como objetivo observar a dinâmica entre eles, desde a decisão sobre qual local representar no desenho até a forma de execução do mesmo, verificando se ocorria uma parceria ou se havia uma das partes que liderava o processo. Outros aspectos que puderam ser trabalhados foram a aprovação ou desaprovação dos pais em relação ao que as crianças faziam, ou seu contrário, e se realmen- te existiam momentos em que compartilhavam experiências agradáveis que pudessem ser colocadas no papel. No decorrer dos atendimentos, os fenômenos que se manifestaram foram explorados por meio do favorecimento do diálogo entre criança-responsável, destacando-se a importância deste para o desenvolvimento da criança.

Uma atividade que merece ser destacada refere-se à utilização de fantoches para a construção de histórias. Em sessões anteriores ao encontro com os pais, os membros do grupo criaram e ensaiaram uma trama com tema livre, para ser apresentada àqueles. No dia da exposição, os pais poderiam escolher outro personagem à disposição, para participar do enredo. Os objetivos da proposição foram trabalhar a disponibilidade dos pais de integrarem-se às fantasias das crianças, contribuindo com suas ideias, verificar o movimento relacional das famílias e compreender a reação das crianças diante da entrada dos adultos na esfera lúdica.

No último encontro com os pais foi feita uma avaliação, na qual discutiu-se, na presença das crianças, o que lhes significou o processo psicoterapêutico vivido; tendo como referência o aqui-agora, perguntou-se aos pais como eles percebiam seus filhos quando chegaram para o processo, como os percebiam naquele momento e o que ainda esperavam, envolvendo, assim, os responsáveis na avaliação e encaminhamento do processo do filho, indicando-lhe a alta ou a continuidade do tratamento.

Buscando-se um trabalho integral com o indivíduo e de maior resolubilidade dos serviços, utilizou-se da clínica ampliada, participando-se da reunião semanal de Equipe de Saúde da Família (ESF) e de Equipe de Saúde Mental (SM), em que se teve a oportunidade de obter trocas de conhecimento com profissionais de diferentes áreas (agentes comunitários de saúde, enfermeiros, auxiliares de enfermagem, médicos, terapeuta ocupacional e nutricionistas). Eram discutidos casos com o objetivo de integrar a equipe na decisão de qual encaminhamento seria o mais adequado, além de ampliar as formas de atenção dedicadas aos usuários. Com isso, foi nítida a percepção da importância de todos os profissionais envolvidos com a saúde na promoção de qualidade de vida da comunidade.

Além disso, foi feito um trabalho intersetorial envolvendo a escola, quando necessário, para a compreensão das experiências vividas pela criança e suas outras formas de expressão que não somente a do âmbito da saúde. Esta demanda foi identificada a partir do grande número de crianças encaminhadas pelas escolas do território, com queixas relacionadas à processo de aprendizagem ou relações interpessoais no âmbito escolar. O contato com professores, diretores e coordenadores possibilitou a realização de matriciamento intersetorial e a ação interdisciplinar.

A experiência relatada possibilitou a identificação da importância de um trabalho que valorize a criança em sua individualidade, considerando o contexto histórico- 
cultural no qual está inserida, sendo necessário, portanto, uma atenção integral à saúde.

\section{Considerações Finais}

Analisando a prática vivenciada nos atendimentos com grupo de crianças em uma Unidade Básica de Saúde, foi possível observar a identidade entre a clínica gestáltica e os princípios do SUS, visto que ambos preconizam o indivíduo na sua unicidade, constituído por dimensões objetivas, tais como orgânicas e do contexto histórico-cultural, e as subjetivas, tais como as experiências vividas, os desejos e as expectativas de futuro; esta constituição de indivíduo, denominada subjetividade, faz-se ação sempre no aqui-agora: nas relações familiares, escolares, amizades, afetos, sonhos, fantasias, dentre tantas outras ações que geram, por sua vez, novas experiências que virão a constituir subjetividade, num constante vir-a-ser.

Acredita-se que para o bom desenvolvimento da clínica infantil, o setting terapêutico deve estabelecer um ambiente de respeito mútuo, segurança e confiança entre as crianças e entre as crianças e o terapeuta, favorecendo, assim, a valorização de suas potencialidades e, ao mesmo tempo, o estabelecimento de regras e limites que estão presentes na convivência social. Desta forma, as vivências, em sessão, das dimensões objetivas e subjetivas de constituição da subjetividade, favorecem, também, o desenvolvimento de ajustamento criativo diante da percepção de si mesmo e do outro, o que é essencial para a possível ampliação de awareness de cada membro do grupo e do próprio grupo. Assim, a tentativa da formação de um bom vínculo desde o início é fundamental neste processo.

Por último, ressalta-se a importância da participação dos responsáveis pelas crianças, no decorrer da psicoterapia, para que as intervenções fossem mais satisfatórias no desenvolvimento de autoconhecimento e das relações dialógicas, tendo em vista que a família é um dos elementos de grande influência no campo holístico da criança, considerando-se as dimensões objetivas do contexto histórico-cultural na constituição da subjetividade.

\section{Referências}

Aguiar, L. (2005). Gestalt-terapia com crianças: teoria e prática. Campinas: Livro Pleno.

Antony, S. (2010). Um caminho terapêutico na clínica gestáltica com crianças. Em S. Antony (Org.), Clínica gestáltica com crianças: caminhos de crescimento (pp. 80-105). São Paulo: Summus.

Benjamin, A. (2004). A Entrevista de Ajuda. São Paulo: Martins Fontes.
Ministério da Saúde / Secretaria Nacional de Assistência à Saúde (1990). ABC do SUS: Doutrinas e Princípios. Brasília: Autor

Ministério da Saúde. Brasília / Ministério da Saúde / Secretaria de Atenção à Saúde (1997). Portaria no 1.886/1997. Aprova as Normas e Diretrizes do Programa de Agentes Comunitários de Saúde e do Programa de Saúde da Família. Brasília: Autor.

Ministério da Saúde / Secretaria de Atenção à Saúde / Departamento de Atenção Básica (2006). Política nacional de atenção básica. Brasília: Autor.

D’Acri, G. (2007). A concepção de sintoma à luz da gestalt-terapia. Revista IGT na Rede, 4(7), 117-120.

Figueiredo, M. D., \& Campos, R. O. (2009). Saúde mental na atenção básica à saúde de Campinas: uma rede ou um emaranhado? Ciência \& Saúde Coletiva, 14(1), 129-138.

Juliano, J. C. (1999). A arte de restaurar histórias: o diálogo criativo no caminho pessoal. São Paulo: Summus.

Lizias, S. (2010). Epistemologia Gestáltica e a prática clínica com crianças. Em S. Antony, (Org.), Clínica gestáltica com crianças: caminhos de crescimento (pp. 47-77). São Paulo: Summus.

Oaklander, V. (1980). Descobrindo crianças: a abordagem gestáltica com crianças e adolescentes. São Paulo: Summus.

Ribeiro, J. P. (1994). Gestalt-terapia - O processo grupal. São Paulo: Summus.

Rodrigues, H. E. (2000). Introdução à Gestalt-terapia. Petrópolis: Vozes.

Tanaka, O. Y., \& Ribeiro, E. L. (2009). Ações de saúde mental na atenção básica: caminho para ampliação da integralidade da atenção. Ciência \& Saúde Coletiva, 14(2), 477-486.

Bruna Gonçalves Campos - Discente Estagiária de Psicologia da Pontifícia Universidade Católica de Campinas. Email:

Tatiana Bruno de Toledo - Discente Estagiária de Psicologia da Pontifícia Universidade Católica de Campinas. Email:

Nilton Júlio de Faria - Doutor em Psicologia Social pela Pontifícia Universidade Católica de São Paulo; Docente da Pontifícia Universidade Católica de Campinas. Endereço Institucional: PUC-Campinas, Centro de Ciências da Vida - Faculdade de Psicologia. Av. John Boyd Dunlop $\mathrm{s} / \mathrm{n}^{\mathrm{o}}$ - Jardim Ipaussurama - CEP: 13.059-900 - Campinas-SP. Email: nfaria@uol.com.br

Recebido em 15.04.11

Primeira Decisão Editorial em 28.06.11

Aceito em 26.07.11 